\title{
A
}

Volume: 1, Issue: 2, June 2016, Pages: 40-43, DOI: http://dx.doi.org/10.19082/ah40

\section{CLOSED CAPSULE GENTAMICIN LAVAGE AS A SUCCESSFUL UNUSUAL THERAPY FOR PACEMAKER POCKET ABSCESS: A CASE REPORT}

\author{
Ali Talib ${ }^{1}$, Samer Talib ${ }^{2}$
}

1: Medical Student, Maastricht University, Maastricht, The Netherlands

2: M.D., Cardiologist, General Hospital Diest, Eindhoven, The Netherlands

\section{TYPE OF ARTICLE: CASE REPORT}

\begin{abstract}
Introduction: Standard treatment for pacemaker pocket abscess is a surgical complete pacemaker system explantation and prolonged systemic antibiotic therapy. This is expensive and not always feasible. The aim of this study was to describe a new alternative treatment method for pacemaker pocket abscess.

Case presentation: We present an 80-year-old woman with a history of heart failure, now with a staphylococcus aureus positive pacemaker pocket abscess. Referral to surgery for pacemaker explantation was not directly possible, due to the physical and mental state of the patient. Systemic gentamicin therapy was impossible, as a result of renal failure. A minimally invasive lavage treatment was thus performed. The pacemaker pocket abscess was punctured whilst maintaining the structural integrity of the abscess wall. After a closed lavage regimen of four weeks, there was no sign of recurrence of the infection. After one year follow-up, the patient is free of local or systemic infections. To our knowledge, this is the first report of this method of minimally invasive percutaneous closed abscess lavage.

Conclusion: Gentamicin lavage of a pacemaker pocket abscess may be a feasible treatment option if a surgical pacemaker system explantation is not possible.

KEYWORDS: Pacemaker pocket abscess, Closed capsule gentamicin lavage, Irrigation, Staphylococcus aureus infection
\end{abstract}

\section{INTRODUCTION}

Infection of implanted cardiac devices (ICDs) remains an important medical problem, with an infection rate of approximately $1 \%(1-3)$. ICD infections are associated with a significantly higher risk of morbidity and mortality, as well as increased health care costs $(4,5)$. Such infections may present as a local abscess in the pacemaker pocket area. The standard of care for ICD infection is complete pacemaker system explantation and systemic antibiotic administration $(6,7)$. This therapy is not always possible, however, due to pacemaker dependency or comorbidities. This case presents an alternative, minimally invasive treatment method for pacemaker pocket abscess. In this method, the abscess is lavaged under maintenance of the structural integrity of its wall.

\section{CASE PRESENTATION}

\subsection{Patient Characteristics}

An 80-year-old woman with a history of heart failure and paroxysmal atrial fibrillation was set on heart failure therapy, including Cordarone, diuretics, and Pradaxa, a new oral anticoagulant drug. Conversion to sinus rhythm was complicated with pronounced symptomatic bradycardia with pauses (i.e. $>3$ s), tachy-brady syndrome. She, therefore, received a pacemaker implantation (Boston Scientific VITALIO MRI).

\subsection{Clinical Findings}

One month later, she was admitted to the department of pulmonology with a staphylococcus aureus pneuma-sepsis. Upon admission, the patient was seriously dehydrated with renal insufficiency. Her lab values were creatinine 3.13

\section{Correspondence:}

Dr. Samer Talib, Cardiologist, General Hospital Diest, Eindhoven, The Netherlands.

Tel: +31.644791464, E-mail: samer.talib@azdiest.be

Received March 27, 2016, Accepted: May 15, 2016, Published: June 2016

iThenticate screening: March 29, 2016, English editing: May 18, 2016, Quality control: May 19, 2016

(C) 2016 The Authors. This is an open access article under the terms of the Creative Commons Attribution-NonCommercialNoDerivs License, which permits use and distribution in any medium, provided the original work is properly cited, the use is non-commercial and no modifications or adaptations are made. 
$\mathrm{mg} / \mathrm{dL}$, eGFR $14 \mathrm{ml} / \mathrm{min} / 1.73 \mathrm{~m}^{2}$, CRP $239 \mathrm{mg} / \mathrm{L}$. Pradaxa was discontinued, due to the renal insufficiency. Therapy was initiated with ceftriaxone for one week.

Despite clinical recovery during this period, with a decrease of dyspnea complaints and a decrease in CRP, a progressively enlarging swelling appeared in her pacemaker pocket.

\subsection{Diagnostic Focus and Assessment}

Because of recent use of oral anticoagulation and renal insufficiency, a pacemaker pocket hematoma was considered. An aspiration was applied to the swelling. Surprisingly, a mucopurulent fluid was aspired, rather than blood. Bacteriological study of the aspired fluid showed staphylococcus aureus, which is sensitive to gentamicin and ofloxacin. This was, therefore, a pacemaker pocket abscess, a highly adverse finding.

\subsection{Therapeutic Focus and Assessment}

A pacemaker pocket abscess is comparable with endocarditis and thus requires the same treatment regime. The standard therapy for such an abscess is a surgical pacemaker system explantation and antibiotic therapy for at least six weeks. Transesophageal echography did not show vegetation on the heart valves or pacemaker wires. Despite the infection, there also was no pacemaker dysfunction. A referral for pacemaker explantation in a tertiary referral centre was considered but refused by the family, due to the poor clinical condition, anxiety disorder, and dementia of the patient. Therapy with intravenous ofloxacin was initiated. Due to severe renal dysfunction, systemic use of gentamicin was not possible. A unique method of abscess gentamicin lavage was initiated, using a thick aspiration needle (BD Microlance 3, 18G 1/2,", 1, 2x40mm). Aside from the puncture site of the aspiration needle, the structural integrity of the abscess and surrounding tissues was maintained. The patient underwent pocket aspiration and lavage three times per week with the use of this aspiration needle. Per session, three lavages of 20 mg gentamicin each were performed, over a period of four weeks. This resulted in amelioration of the clinical condition with normalisation of CRP. The patient was discharged after four weeks. Additionally, oral floxapen was administered for two weeks thereafter.

\subsection{Follow-up and Outcomes}

On short-term follow-up, there were no indicators of recurrent abscess formation. CRP and infection parameters remained normal with adequate pacemaker function. On one-year follow-up, the patient was healthy, without scar formation (Figure 1), free of infection and with good pacemaker functioning.

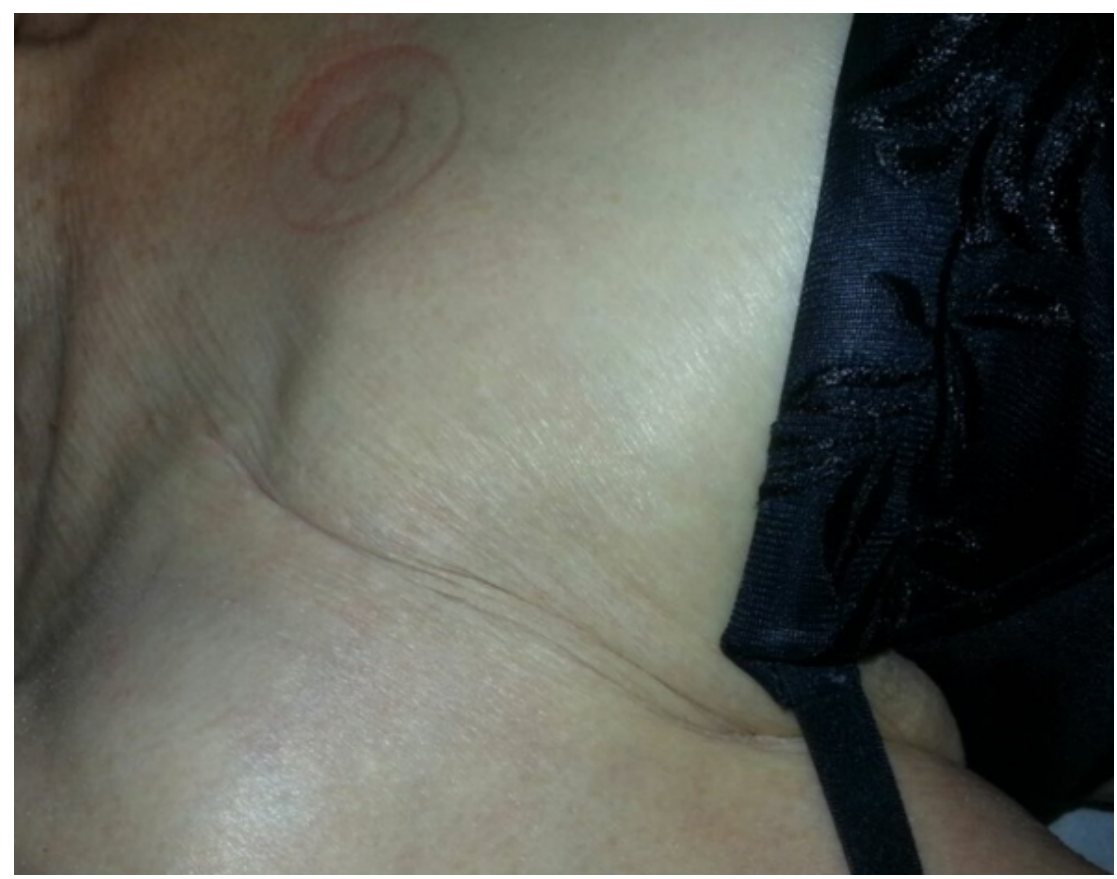

Figure 1. Patient one-year follow-up: no scarring can be seen. The red marks are temporary, due to recently placed electrocardiogram leads. 


\section{DISCUSSION}

This case describes a minimally invasive percutaneous antibiotic lavage approach to treating a pacemaker pocket abscess, whereby the abscess capsule remains intact. To our knowledge, this precise approach has not been reported in the literature. Other percutaneous treatment methods for a pacemaker pocket abscess have been reported, however (7-9). Recently, Lopez (3) demonstrated percutaneous treatment of a pocket infection by removal of all inflammatory tissue, followed by complete sterilization of the device hardware (by scrubbing, pulsed lavage, and antimicrobial therapy), and, subsequently, a three-day closed antibiotic lavage of the pocket to ensure sterilization. This method was applied to five patients, all of whom had a negative infection status after longer than 12 months follow-up. This outcome is comparable to the outcome with our method. However, the method described by Lopez (3) is more invasive and destroys the abscess wall. Our method utilizes the workings of the innate immune system: the abscess. The abscess is formed to effectively entrap the infection locally. By incising only a limited portion of the abscess capsule (formed by healthy cells), while leaving the rest intact, a minimally invasive closed lavage can be performed. This conservative approach was safely applied on this patient, with excellent long-term outcomes. The literature on the topic of percutaneous treatment of pacemaker pocket abscess is scarce. For more evidence of the efficacy and safety of percutaneous treatment methods, such as our closed-capsule pacemaker pocket lavage, randomized clinical trials are necessary.

\section{CONCLUSIONS}

Closed capsule gentamicin lavage may be an effective alternative treatment for pacemaker pocket abscess in those for whom surgical pacemaker system explantation is not feasible, due to patient characteristics or insufficient healthcare resources. Randomized clinical trials are necessary to provide an evidence base for the safety and efficacy of this method.

\section{ACKNOWLEDGMENTS:}

No acknowledgments to be reported.

\section{CONFLICT OF INTEREST:}

There is no conflict of interest to be declared.

\section{AUTHORS' CONTRIBUTIONS:}

All authors contributed to this project and article equally. All authors read and approved the final manuscript.

\section{REFERENCES:}

1) Polyzos KA, Konstantelias AA, Falagas ME. Risk factors for cardiac implantable electronic device infection: a systematic review and meta-analysis. Europace. 2015; 17(5): 767-77. doi: 10.1093/europace/euv053. PMid: 25926473.

2) Bongiorni MG, Marinskis G, Lip GY, Svendsen JH, Dobreanu D, Blomström-Lundqvist C, et al. How European centres diagnose, treat, and prevent CIED infections: results of an European Heart Rhythm Association survey. Europace. 2012; 14(11): 1666-9. doi: 10.1093/europace/eus350. PMid:23104858.

3) Lopez JA. Conservative management of infected pacemaker and implantable defibrillator sites with a closed antimicrobial irrigation system. Europace. 2013; 15(4): 541-5. doi: 10.1093/europace/eus317. PMid:23015633.

4) Fakhro A, Jalalabadi F, Brown RH, Izaddoost SA, editors. Treatment of Infected Cardiac Implantable Electronic Devices. Seminars in plastic surgery; 2016; 30(02): 60-5. doi: 10.1055/s-0036-1580733.

5) Rizwan Sohail M, Henrikson CA, Jo Braid-Forbes M, Forbes KF, Lerner DJ. Increased long-term mortality in patients with cardiovascular implantable electronic device infections. Pacing and clinical electrophysiology : PACE. 2015; 38(2): 231-9. PMid: 25243484.

6) Aydin M, Yildiz A, Kaya Z, Kaya Z, Basarir AO, Cakmak N, et al. Clinical Characteristics and Outcome of Cardiovascular Implantable Electronic Device Infections in Turkey. Clinical and applied thrombosis/hemostasis : official journal of the International Academy of Clinical and Applied Thrombosis/Hemostasis. 2016; 22(5): 459-64. PMid: 25589093.

7) Kennergren C. Management of Cardiovascular Implantable Electronic Devices Infections in High-Risk Patients. Arrhythmia \& electrophysiology review. 2015; 4(1): 53-7. PMID: 26835101. PMCid: PMC4711570.

8) Margey R. Cardiac implantable electronic device infections: the enemy that lurks beneath the skin. Journal of long-term effects of medical implants. 2010; 20(3): 203-17. PMid: 21395519. 
9) Leung S, Danik S. Prevention, Diagnosis, and Treatment of Cardiac Implantable Electronic Device Infections. Current cardiology reports. 2016; 18(6): 58. PMid: 27147510.

10) Bongiorni MG, Marinskis G, Lip GY, Svendsen JH, Dobreanu D, Blomström-Lundqvist C, et al. How European centres diagnose, treat, and prevent CIED infections: results of an European Heart Rhythm Association survey. Europace. 2012; 14(11): 1666-9. doi: 10.1093/europace/eus350. PMid:23104858. 